\title{
CARACTERIZAÇÃO DE PLANTAS E DE FRUTOS DE ARATICUNZEIRO (Annona crassiflora Mart.) NATIVOS NO CERRADO MATOGROSSENSE ${ }^{1}$
}

\author{
ALEX CAETANO PIMENTA ${ }^{2}$, PATRICIA SEDREZ DA ROSA E SILVA ${ }^{3}$, \\ KATIA CHRISTINA ZUFFELLATO-RIBAS ${ }^{4}$, HENRIQUE SOARES KOEHLER ${ }^{5}$
}

RESUMO - O araticunzeiro (Annona crassiflora Mart - Annonaceae) é uma frutífera nativa do cerrado brasileiro que necessita de estudos visando à geração de dados para subsidiar pesquisas relativas à sua domesticação. Com o presente trabalho, objetivou-se estudar uma população de araticunzeiro em relação ao diâmetro do caule e altura das plantas, à produção e às características físicas e químicas de frutos. Nas plantas, mensuraram-se diâmetro do caule, altura e produção de frutos. Nos frutos, analisaram-se os diâmetros longitudinal (DL) e transversal (DT), a relação DL/DT, as massas do fruto, da casca, da semente e da polpa, e calculou-se o rendimento de polpa. Na polpa, efetuaram-se as determinações de sólidos solúveis (SS), acidez titulável (AT), relação SS/AT, pH e umidade. As árvores possuem diâmetro do caule de 10,4 $\pm 3,1$ $\mathrm{cm}$ e altura de $3,7 \pm 0,7 \mathrm{~m}$ com produção média de $6,0 \pm 3,6$ frutos por planta. Em média, os frutos possuem

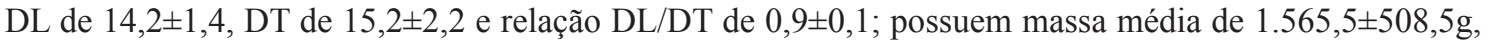
tendo as massas da casca, das sementes e da polpa médias de 662,2 $\pm 198,2 \mathrm{~g}, 179,8 \pm 66,2 \mathrm{~g}$ e $723,5 \pm 276,7 \mathrm{~g}$,

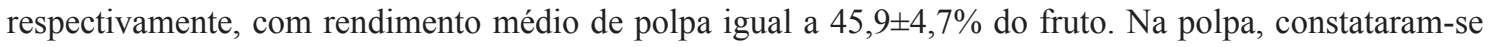

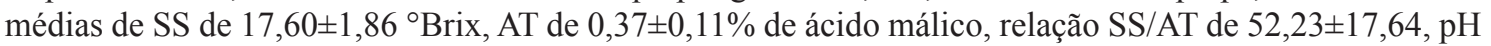
de 4,45 $\pm 0,23$ e umidade média igual a $74,3 \pm 2,86 \%$. O araticunzeiro possui características físicas e químicas que o tornam uma alternativa para a fruticultura nativa brasileira.

Termos para indexação: araticum, marolo, polpa, Brix.

\section{CHARACTERIZATION OF PLANTS AND FRUIT OF ARATICUM PLANT (Annona crassiflora Mart.) NATIVE TO THE CERRADO OF MATO GROSSO}

\begin{abstract}
The araticunzeiro (Annona crassiflora Mart - Annonaceae) is a native fruit from the Brazilian Cerrado requiring studies to generate data to support research related to its domestication. This research aimed to study a population of araticunzeiro relating to the stem diameter and plant height, production, and physical and physical-chemical characterization of its fruits. Diameter of stem, height, and fruit yield of plants were measured. In the fruits, longitudinal (LD) and transverse (TD) diameters, the LD/TD ratio, the masses of fruit, peel, seed, and pulp were analyzed; and the pulp yield was calculated. In the pulp, determination of soluble solids (SS), titratable acidity (TA), SS/TA ratio, $\mathrm{pH}$, and moisture were performed. The trees had stem diameter of $10.4 \pm 3.1 \mathrm{~cm}$ and height of $3.7 \pm 0.7 \mathrm{~m}$ with an average yield of $6.0 \pm 3.6$ fruits per plant. On average, fruits presented 14.2 $\pm 1.4 \mathrm{LD}, 15.2 \pm 2.2 \mathrm{TD}$, and $0.9 \pm 0.1 \mathrm{LD} / \mathrm{TD}$ ratio; they presented $1,565.5 \pm 508.5 \mathrm{~g}$ average mass; and masses of peel, seeds, and pulp presented $662.2 \pm 198.2 \mathrm{~g}, 179.8 \pm 66.2 \mathrm{~g}$, and $723.5 \pm 276.7 \mathrm{~g}$ averages, respectively, with average pulp yield equal to $45.9 \pm 4.7 \%$ of the fruit. In pulp, $\mathrm{SS}$ average of $17.60 \pm 1.86^{\circ}$ Brix, TA of $0.37 \pm 0.11 \%$ malic acid, SS/TA ratio of $52.23 \pm 17.64,4,45 \pm 0.23 \mathrm{pH}$, and average humidity equal to $74.3 \pm 2.86 \%$.. The araticunzeiro has physical and chemical characteristics that make it an alternative to the native Brazilian fruit production.
\end{abstract}

Index terms: araticum, marolo, pulp, Brix.

\footnotetext{
${ }^{1}$ (Trabalho 416-13). Recebido em: 17-10-2013. Aceito para publicaçaõ em: 26-03-2014.

${ }^{2}$ Professor do IFMT Campus São Vicente, doutor em Agronomia - Produção Vegetal, Setor de Ciências Agrárias, Departamento de Fitotecnia e Fitossanitarismo, Universidade Federal do Paraná. CEP 80035-050, Curitiba - PR. e-mail: profpimenta@hotmail.com

${ }^{3}$ Agrônoma do IFMT Campus São Vicente. e-mail: patricia.sedrez@svc.ifmt.edu.br

${ }^{4}$ Professora do Departamento de Botânica, Setor de Ciências Biológicas, Universidade Federal do Paraná, Curitiba - PR. e-mail: kazu@ufpr.br

${ }^{5}$ Professor do Departamento de Fitotecnia e Fitossanitarismo, UFPR, Curitiba, PR, Brasil. e-mail: koehler@ufpr.br
} 


\section{INTRODUÇÃO}

A competitividade e o potencial do Brasil na produção de alimentos são reconhecidos em todo o mundo, especialmente em relação à fruticultura, que se mostra vantajosa para grandes e pequenos produtores, constituindo-se em importante meio de geração de renda no campo (CARVALHO, 2009). A fruticultura brasileira posiciona-se em terceiro lugar quanto à produção mundial de frutas, revelando seu enorme potencial para expandir-se no mercando internacional, principalmente com a divulgação e inserção de frutas exóticas nesses mercados (BUENO; BACCARIN, 2012).

O Brasil apresenta grande diversidade de frutíferas nativas, porém sem expressão e produção significativas, devido à falta de conhecimentos que permitam introduzi-las como plantas cultivadas. Paralelamente, observa-se a crescente busca dos produtores por novas opções de cultivo, ao passo que se constata aumento na procura de frutas exóticas por parte dos consumidores (ANDRADE et al., 2009). Entretanto, inserir uma nova espécie como planta cultivada exige previamente conhecê-la em seus aspectos morfológicos e comportamentais no ambiente natural.

O conhecimento da produtividade é fundamental para caracterizar a produção final de determinada espécie sendo, portanto, uma variável elementar para o desenvolvimento de cultivos agrícolas e programas de seleção e melhoramento de espécies de interesse comercial (SANTOS; CAMARGO, 2006). O conhecimento das características físicas e químicas dos alimentos, tradicionalmente consumidos pela população, é de suma importância no que diz respeito à orientação nutricional, ao controle de qualidade do alimento e subsidia a identificação das espécies promissoras, tendo em vista seu aproveitamento industrial e a aplicação de estudos de melhoramento genéticos (OLIVEIRA et al., 2010).

Nativo do Cerrado brasileiro, o araticunzeiro (Annona crassiflora Mart. - Annonaceae), conhecido popularmente como marolo, araticum e pinha-docerrado, é uma planta com potencial para utilização em sistemas tradicionais de produção agrícola. Seus frutos são muito apreciados nas regiões de ocorrência, por apresentarem ótimo aroma e sabor, digestibilidade e alto valor nutritivo, com elevados teores de açúcares, proteínas, vitaminas e sais minerais, podendo ser consumidos in natura ou na forma de sucos, licores sorvetes e geleias (TELLES et al., 2003). Entretanto, embora portador dessas características, o araticunzeiro continua a ser explorado de forma essencialmente extrativista, sendo conhecido e consumido somente nas regiões de ocorrência espontânea. Trata-se de uma espécie não domesticada, de polinização cruzada e que naturalmente deve apresentar grande variabilidade para algumas características em relação à planta, à produção e aos frutos.

Assim, com o presente trabalho, objetivou-se estudar uma população de araticunzeiro em relação ao diâmetro do caule e altura das plantas, à produção e às características físicas e físico-químicas de frutos, para a obtenção de dados que sirvam de subsídio a futuras pesquisas referentes à domesticação da espécie.

\section{MATERIAL E MÉTODOS}

A presente pesquisa foi desenvolvida no Instituto Federal de Educação, Ciência e Tecnologia de Mato Grosso, Câmpus São Vicente, em Santo Antônio do Leverger-MT, e na Universidade Federal do Paraná, em Curitiba-PR. As matrizes foram selecionadas de uma população nativa de araticunzeiro, localizada na fazenda Cascata do Andorinha e situada nas coordenadas geográficas $15^{\circ} 50^{\prime} \mathrm{S}$ e $55^{\circ} 21^{\prime} \mathrm{W}$, numa altitude de $770 \mathrm{~m}$. A reserva possui aproximadamente 730 ha, formando um mosaico com as diferentes fitofisionomias do bioma Cerrado.

Para a demarcação das plantas-matrizes fezse o reconhecimento da área de estudo aplicando-se o método de caminhamento (FILGUEIRAS et al., 1994), e os espécimes foram georreferenciados com o uso de GPS Garmin 72. Em setembro de 2010, foram identificadas e demarcadas 50 plantas no estádio reprodutivo, baseando-se na presença de flor e/ou de fruto. Neste trabalho, foram desprezadas as plantas que não concluíram o ciclo de reprodução anual, considerando-se dados de 34 plantas. Dessas plantas, foram obtidos diâmetro do caule (aproximadamente $130 \mathrm{~cm}$ do solo) e altura da planta (do solo à extremidade do ramo mais alto). Em fevereiro de 2011, realizou-se a contagem do número de frutos por planta, considerando-se todos os frutos presentes, independentemente do tamanho, para a determinação da produção.

De fevereiro a março de 2012, foram selecionados ao acaso seis frutos coletados imediatamente após desprenderem-se da plantamatriz, e estes tiveram suas dimensões longitudinal (diâmetro longitudinal - DL) e transversal (diâmetro transversal - DT) medidas com paquímetro digital graduado de $30 \mathrm{~cm}$ e precisão de $0,001 \mathrm{~cm}$. A partir desses valores, calculou-se a relação DL/DT. Os 
frutos tiveram suas massas mensuradas em balança digital com capacidade para seis quilos e precisão de $0,002 \mathrm{~g}$, onde se mensurou também as partes que os compõem, após despolpa manual. Foram consideradas as massas da casca (epicarpo), da polpa (mesocarpo, endocarpo e pedúnculo) e da semente, sendo os resultados apresentados em gramas. Calculou-se o rendimento de polpa (massa polpa/ massa do fruto), com o resultado apresentado em porcentagem.

A polpa dos frutos foi embalada individualmente, congelada a aproximadamente $-18{ }^{\circ} \mathrm{C}$ e transportada a Curitiba, onde se processaram as avaliações químicas. As amostras foram descongeladas em geladeira e trituradas em multiprocessador doméstico, seguindo-se as determinações de: sólidos solúveis (SS), determinado por refratometria, utilizando-se de refratômetro RHB-32 ATC com escala de $0-32 \%$ e ajustado à temperatura ambiente, sendo os resultados expressos em ${ }^{\circ}$ Brix; acidez titulável (AT), determinada por titulação em bureta, conforme normas do Instituto Adolfo Lutz (2005), e os resultados, expressos em porcentagem de ácido málico; relação entre os teores de sólidos solúveis e a acidez titulável (SS/ $\mathrm{AT}) ; \mathrm{pH}$, realizado em pHmetro digital de bancada pHtek, modelo PHS-3B, previamente calibrado com as soluções 4 e 7 , e teor de umidade, obtido por secagem de $10 \mathrm{~g}$ da amostra em estufa, a $70{ }^{\circ} \mathrm{C}$, até atingir massa constante, sendo o resultado expresso em porcentagem. Todas as análises químicas e a determinação de umidade foram realizadas em triplicatas.

Os dados obtidos foram analisados, utilizandose da estatística descritiva, com determinação dos valores mínimo, médio e máximo com seus respectivos desvios-padrão e coeficientes de variação, para cada variável. Os valores encontrados para diâmetro do caule e altura das plantas foram agrupados em classes, com amplitudes de 3,1 cm e $0,7 \mathrm{~m}$, respectivamente. As correlações entre as variáveis foram estimadas pelo coeficiente de correlação de Pearson.

\section{RESULTADOS E DISCUSSÃO}

As plantas de araticunzeiro, de modo geral, apresentaram heterogeneidade em relação ao diâmetro do caule, à altura das plantas e à produção, sendo produção a característica que apresentou maior variabilidade (Tabela 1). Tais resultados já eram previstos, haja vista que são oriundos de uma população nativa, desenvolvida naturalmente no ambiente, propagada por sementes, de polinização cruzada e sem qualquer tipo de interferência agronômica. É importante observar que diâmetro, altura e produção são variáveis controladas por múltiplos genes que determinam a herança quantitativa do caráter. Além disso, em florestas nativas há grande diversidade de espécies, disposição de luminosidade distinta e outros fatores ambientais preponderantes que podem ter influenciado esta elevada diferenciação (LIMA; LEÃO, 2013).

$\mathrm{O}$ diâmetro médio do caule e a altura média das plantas foram de $10,4 \pm 3,1 \mathrm{~cm}$ e $3,7 \pm 0,7 \mathrm{~m}$, respectivamente (Tabela 1), com forte correlação entre essas variáveis (Tabela 2). Na análise dos dados agrupados (Tabela 1), observou-se que as maiores frequências se localizam nas classes intermediárias do agrupamento, sendo a classe diamétrica de 10,7 - 13,9 cm aquela que apresentou o maior número de indivíduos (35,3\%). Em relação à altura das plantas, foi constatado o maior número de indivíduos $(38,2 \%)$ compreendidos entre 3,7 e 4,4 m. De modo geral, todas as classes, tanto para diâmetro do caule quanto para altura das plantas, estão bem representadas, sendo as maiores e as menores frequências encontradas de 17,6\% para ambas as variáveis.

A classificação obtida neste trabalho difere daquela esperada, uma vez que florestas nativas geralmente apresentam maior número de indivíduos nas classes menores (LIMA; LEÃO, 2013). Porém, Vale et al. (2009) verificaram que, no bioma Cerrado, as espécies não seguem um padrão definido de distribuição e que a resposta é dependente do tipo de regeneração. Segundo Figueiredo et al. (2010), áreas em regeneração começam a apresentar indivíduos nas classes iniciais somente após oito anos da exploração, coincidindo com a área em estudo, que deixou de sofrer ação antrópica e os impactos do fogo, a partir de 2003, conforme registros do proprietário.

Em relação à produção de frutos, constatouse média de seis frutos por planta (Tabela 1), valor relativamente baixo em se tratando de fruticultura. Embora baixa, produção média similar $(6,53$ frutos/planta) foi encontrada por Braga-Filho et al. (2009) em populações naturais de araticunzeiro localizadas no Estado de Goiás. Braga-Filho et al. (2009) afirmam que a produção é uma característica influenciada por vários fatores, cuja variação se estabelece entre plantas e entre populações, e carece de estudos que incluam a influência do ambiente. Além disso, o araticunzeiro possui sazonalidade reprodutiva que, segundo Braga-Filho et al. (2009), é variável entre os anos. Essa condição determina a necessidade de se estudar a produção de frutos por alguns ciclos consecutivos. 
Considerando a produção de frutos de araticunzeiro em função do porte da planta (diâmetro do caule e altura), não se observaram correlações significativas entre essas variáveis (Tabela 2). Essa condição permite inferir que a espécie tem potencial para se estabelecer como frutífera comercial, pois apresenta porte requerido sem afetar a produção de frutos, dispensando pesquisas relacionadas à sua arquitetura e, portanto, minimizando tempo e custo na domesticação. Todavia, é importante a confirmação desta informação ao longo de alguns ciclos de produção, tendo em vista a sazonalidade reprodutiva que a espécie possui.

Os dados médios encontrados para diâmetro longitudinal $(14,2 \mathrm{~cm})$, diâmetro transversal $(15,2$ $\mathrm{cm})$ e a relação DL/DT $(0,9)$ (Tabela 3$)$ indicam que os frutos de araticunzeiro possuem forma globosa a subglobosa, característica comum à espécie, conforme Lima-Britto et al. (2006). A forma arredondada de frutos caracteriza-se à medida que o valor da relação DL/DT se aproxima de um e, segundo Chitarra e Chitarra (2005), é uma característica desejável e importante em se tratando de frutos destinados à industrialização, pois facilita as operações de limpeza e de processamento.

Os frutos de araticunzeiro são considerados grandes, com massa variável entre $771,0 \mathrm{~g}$ a $2.113,0$ $\mathrm{g}$, sendo a média igual a $1.565,5$ (Tabela 3). Essa massa total está distribuída em casca, sementes e polpa, com médias de $662,2 \mathrm{~g}, 179,8 \mathrm{~g}$ e $723,5 \mathrm{~g}$, respectivamente, sendo que a polpa representa, em média, $45,9 \%$ do fruto (Tabela 3 ). O rendimento de polpa encontrado na presente investigação assemelha-se aos resultados apresentados para outras espécies do gênero, como a pinha (Annona squamosa L.), em que a polpa representa aproximadamente $45 \%$ do fruto (SILVA et al., 2002; ARAÚJO et. al., 2008 ) e de atemoia (Annona cherimola Mill. X A. squamosa L.), cuja polpa compreende entre 45,8 e $63,4 \%$ do fruto (NEVES; YUHARA, 2003).

As estimativas dos coeficientes de correlação foram significativas para todas as variáveis físicas de frutos estudas (Tabela 4). Tais correlações já eram esperadas por se tratar de fruto carnoso, onde dimensões e massas são diretamente proporcionais entre si. Essas informações são importantes, pois podem subsidiar programas de melhoramento genético no que tange à seleção de características adequadas à comercialização e possibilitam inferir sobre mudanças de um caráter a partir da seleção de outro caráter correlacionado (SILVA et al., 2012).

O teor de sólidos solúveis encontrados na polpa de frutos de araticunzeiro variou de 14,33 a $19,50{ }^{\circ}$ Brix, sendo a média de $17,60 \pm 1,86{ }^{\circ}$ Brix
(Tabela 5). O SS médio encontrado no experimento é relativamente inferior ao SS da maioria das espécies de Annonaceae, que contêm aproximadamente 24 ${ }^{\circ}$ Brix (NEVES; YUHARA, 2003; MARCELLINI et al., 2003; SILVA et al., 2007). Porém, o SS é variável entre espécies (MARCELLINI et al., 2003), entre cultivares da mesma espécie (NEVES; YUHURA, 2003; SILVA et al., 2003) e até entre porções do mesmo fruto (SILVA et al., 2003). Ainda em relação ao SS, é importante salientar que os frutos avaliados neste experimento são oriundos de população silvestre, desenvolvidos naturalmente sem qualquer trato cultural.

A acidez titulável da polpa variou de $0,25 \%$ a $0,53 \%$, sendo a média de $0,37 \%$ de ácido málico (Tabela 5), relativamente inferior à média de $0,51 \%$ de ácido cítrico obtida por Cohen et al. (2010). Neste trabalho optou-se por apresentar a acidez titulável em porcentagem de ácido málico, tendo em vista seu predomínio sobre os demais ácidos, conforme relataram Damiani et al. (2011). As diferenças quanto à acidez titulável obtida no presente trabalho em relação aos dados da literatura podem ter relação com a maturação dos frutos usados nos diferentes experimentos, pois, em anonáceas, a maturação de frutos e a acidez titulável parecem ser dependentes entre si, provavelmente devido às mudanças quantitativas e qualitativas ocorridas nos ácidos orgânicos durante o amadurecimento (MOSCA et al., 2006). Esta hipótese explica, inclusive, a alta variação $(C . V .=30,8 \%)$ encontrada no presente experimento (Tabela 5).

A relação SS/AT encontrada no presente estudo variou de 36,79 a 77,33, sendo a média igual a 52,23 (Tabela 5). Observando esses valores, é possível afirmar que a polpa de araticunzeiro possui sabor agradável, tendo em vista que, quanto maior a relação SS/AT, maior é o equilíbrio entre doce e ácido, tornando o fruto mais atrativo ao consumo (KROLOW et al., 2007). A relação SS/AT é uma das melhores formas de avaliação do sabor, sendo mais representativa que a medição isolada de açúcares e de acidez (PINTO et al., 2003).

$\mathrm{O} \mathrm{pH}$ médio encontrado na polpa de frutos de araticunzeiro foi de 4,45 (Tabela 5), similar ao valor de $\mathrm{pH}$ 4,49 obtido por Damiani et al. (2011) e

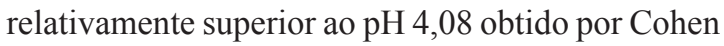
et al. (2010), em frutos da mesma espécie. $\mathrm{O}$ pH obtido no presente estudo permite classificar a polpa de araticunzeiro como ácida a pouco ácida e indica ser um produto de boa qualidade para o consumo in natura e, também, para a indústria que, segundo Santos et al. (2010), utiliza o efeito do $\mathrm{pH}$ sobre os microrganismos para a preservação dos alimentos, 
sendo o $\mathrm{pH} \leq 4,5$ muito importante, pois abaixo desse valor não há desenvolvimento de Clostridium botulinum e de bactérias patogênicas.

A umidade média da polpa de araticunzeiro foi de $74,3 \%$ (Tabela 5), próxima aos valores médios de 74 e $72 \%$ obtidos por Lopes et al. (2012) e de $76 \%$ obtido por Cohen et al. (2010) para a mesma espécie. Segundo Santos et al. (2010), o teor de umidade é uma característica muito importante em frutos, pois é indicativo de como proceder em relação ao manuseio, transporte e processamento, que afetam a estabilidade, a qualidade e a composição do produto.
Não existe legislação específica referente ao Padrão de Identidade e Qualidade (PIQ) para polpa de araticunzeiro, porém é possível fazer comparação entre os dados de algumas variáveis com os dados do PIQ estabelecido para graviola (Annona muricata L.), uma vez que são espécies do mesmo gênero. Brasil (2000) determina somente valores mínimos para SS $\left(9^{\circ} \mathrm{Brix}\right), \mathrm{pH}(3,5)$ e AT expressa em ácido cítrico $(0,60 \mathrm{~g} / 100 \mathrm{~g}$ de polpa). Assim, pode-se afirmar que a polpa de araticunzeiro, exceto em relação à $\mathrm{AT}$, possui características químicas normais em comparação à graviola.

TABELA 1 - Diâmetro do caule, altura da planta e produção de frutos de Annona crassiflora Mart. CuritibaPR.

\begin{tabular}{|c|c|c|c|c|c|c|}
\hline \multicolumn{7}{|c|}{ Diâmetro do caule $(\mathrm{cm})$} \\
\hline Classes & $\mathrm{N}$ & Mínimo & Média & Máximo & $\mathrm{DP}$ & $\mathrm{CV}$ \\
\hline $4,3-7,4$ & 6 & 4,5 & 5,8 & 7,3 & 1,1 & 19,1 \\
\hline $7,5-10,6$ & 10 & 7,6 & 8,9 & 10,5 & 1,0 & 11,3 \\
\hline $10,7-13,8$ & 12 & 10,8 & 11,8 & 13,1 & 0,7 & 6,2 \\
\hline $13,9-17,0$ & 6 & 14,0 & 14,7 & 16,9 & 1,2 & 7,8 \\
\hline Geral & 34 & 4,5 & 10,4 & 16,9 & 3,1 & 29,5 \\
\hline \multicolumn{7}{|c|}{ Altura da planta (m) } \\
\hline Classes & $\mathrm{N}$ & Mínimo & Média & Máximo & $\mathrm{DP}$ & $\mathrm{CV}$ \\
\hline $2,1-2,8$ & 6,0 & 2,2 & 2,5 & 2,8 & 0,2 & 9,5 \\
\hline $2,9-3,6$ & 9,0 & 3,1 & 3,4 & 3,6 & 0,2 & 4,8 \\
\hline $3,7-4,4$ & 13,0 & 3,7 & 4,0 & 4,4 & 0,2 & 5,8 \\
\hline $4,5-5,2$ & 6,0 & 4,5 & 4,6 & 4,9 & 0,2 & 3,5 \\
\hline Geral & 34 & 2,2 & 3,7 & 4,9 & 0,7 & 19,7 \\
\hline \multicolumn{7}{|c|}{ Produção (frutos/planta) } \\
\hline & Mínimo & Média & Máximo & $\mathrm{DP}$ & & $\mathrm{CV}$ \\
\hline Geral & 1,0 & 6,0 & 15,0 & 3,6 & & 60,6 \\
\hline
\end{tabular}

N: número de indivíduos; DP: desvio-padrão; CV: coeficiente de variação.

TABELA 2 - Estimativas dos coeficientes de correlação fenotípicas para diâmetro do caule, altura da planta e produção de frutos de Annona crassiflora Mart. Curitiba-PR.

\begin{tabular}{lccc} 
& Diâmetro do caule $(\mathrm{cm})$ & Altura $(\mathrm{m})$ & Frutos/Planta \\
\hline Diâmetro do caule $(\mathrm{cm})$ & - & 0,7170 & 0,4395 \\
Altura (m) & - & 0,3268 \\
Frutos/Planta & & - \\
\hline
\end{tabular}


TABELA 3 - Diâmetros longitudinal e transversal, relação DL/DT, massas do fruto, da casca, da polpa e das sementes, e rendimento de polpa de frutos de Annona crassiflora Mart. Curitiba-PR.

\begin{tabular}{lccccc}
\hline \multicolumn{1}{c}{ Variável } & Mínimo & Média & Máximo & DP & CV (\%) \\
& & & & & \\
\hline DL $(\mathrm{cm})$ & 12,0 & 14,2 & 16,0 & 1,4 & 10,0 \\
DT $(\mathrm{cm})$ & 11,1 & 15,2 & 17,3 & 2,2 & 14,8 \\
DL/DT & 0,9 & 0,9 & 1,1 & 0,1 & 7,7 \\
MF (g) & 771,0 & $1.565,5$ & $2.113,0$ & 508,5 & 32,5 \\
MC (g) & 284,0 & 662,2 & 844,0 & 198,2 & 29,9 \\
MS (g) & 99,8 & 179,8 & 264,0 & 66,2 & 36,8 \\
MP (g) & 387,2 & 723,5 & $1.066,0$ & 276,7 & 38,2 \\
RP (\%) & 40,8 & 45,9 & 50,8 & 4,7 & 10,3 \\
\hline
\end{tabular}

DL: diâmetro longitudinal; DT: diâmetro transversal; DL/DT: relação entre diâmetro longitudinal e diâmetro transversal; MF: massa do fruto; MC: massa da casca; MS: massa da semente; MP: massa da polpa; RP: rendimento da polpa; DP: desvio-padrão; CV: coeficiente de variação.

TABELA 4 - Estimativa dos coeficientes de correlação fenotípica para diâmetro longitudinal e diâmetro transversal, massas do fruto, da casca, da polpa e das sementes, e rendimento de polpa de frutos de Annona crassiflora Mart. Curitiba-PR.

\begin{tabular}{ccccccc}
\hline & DL & DT & MF & MC & MS & MP \\
\hline DL & - & 0,9327 & 0,9528 & 0,8990 & 0,8740 & 0,8981 \\
DT & & - & 0,9649 & 0,9503 & 0,8746 & 0,8834 \\
MF & & & - & 0,9087 & 0,9034 & 0,9707 \\
MC & & & & - & 0,6976 & 0,7868 \\
MS & & & & & - & 0,9213 \\
MP & & & & & & - \\
\hline
\end{tabular}

DL: diâmetro longitudinal; DT: diâmetro transversal; MF: massa do fruto; MC: massa da casca; MS: massa da semente; MP: massa da polpa.

TABELA 5 - Sólidos solúveis (SS), acidez titulável (AT), relação SS/AT, pH e umidade da polpa de frutos de Annona crassiflora Mart. Curitiba-PR.

\begin{tabular}{cccccc}
\hline Variável & Mínimo & Média & Máximo & DP & CV $(\%)$ \\
\hline SS ( ${ }^{\circ}$ Brix) & 14,33 & 17,60 & 19,50 & 1,86 & 10,6 \\
AT (\%) & 0,25 & 0,37 & 0,53 & 0,11 & 30,8 \\
SS/AT & 36,79 & 52,23 & 77,33 & 17,64 & 33,8 \\
pH & 4,15 & 4,45 & 4,74 & 0,23 & 5,2 \\
Umidade (\%) & 71,80 & 74,30 & 78,80 & 2,86 & 3,9 \\
\hline
\end{tabular}

SS: sólidos solúveis; AT: acidez titulável, em porcentagem de ácido málico; SS/AT: relação entre sólidos solúveis e acidez titulável; pH: potencial de hidrogênio; DP: desvio-padrão; CV: coeficiente de variação. 


\section{CONCLUSÕES}

A maioria dos indivíduos que compõem a população de araticunzeiro estudada possui diâmetro do caule compreendido entre 7,5 e 13,8 cm e altura das plantas variando de 2,9 a 4,4m.

A produção é altamente variável, com média de seis frutos por planta. Essa característica precisa ser explorada, tendo em vista a sazonalidade produtiva da espécie e as condições ambientais.

Os frutos são grandes e arredondados, com significativo rendimento de polpa e características químicas interessantes tanto para o consumo in natura quanto para a indústria.

\section{AGRADECIMENTOS}

À Coordenação de Aperfeiçoamento de Pessoal de Nível Superior - CAPES, pela concessão da bolsa de estudos.

Ao Instituto Federal de Educação, Ciência e Tecnologia de Mato Grosso e à Universidade Federal do Paraná, onde o estudo foi realizado.

Ao senhor Aramy Athayde Cabeleira e família, proprietário da fazenda Cascata do Andorinha, pela cessão da propriedade para o estudo.

\section{REFERÊNCIAS}

ANDRADE, R.A.A.; LEMOS, E.G.M.; MARTINS, A.B.G.; PAULA, R.C. Caracterização morfológica de plantas de rambutan. Acta Scientiarum Agronomy, Maringá, v.31, n.4, p.613-619, 2009.

ARAÚJO, J.F.; LEONEL, S.; PEREITA NETO, J. Adubação organomineral e biofertilização líquida na produção de frutos de pinheira (Annona squamosa L.) no submédio São Francisco, Brasil. Bioscience Journal, Uberlânbia, v.24, n.4, p.48-57, 2008.

BRAGA FILHO, J.R.; NAVES, R.V.; VELOSO, V.R.S.; CHAVES, L.J.; NASCIMENTO, J.L.; AGUIAR, A.V. Produção de frutos e caracterização de ambientes de ocorrência de plantas nativas de araticum no Cerrado de Goiás. Revista Brasileira de Fruticultura, Jaboticabal, v.31, n.2, p.461-473, 2009.

BRASIL. Ministério de Estado da Agricultura e do Abastecimento. Instrução Normativa $\mathrm{n}^{\circ}$. 1, de 07 de janeiro de 2000. Diário Oficial da União, Brasília, DF,10 de jan. de 2000. Seção 1, p.54-58. Disponível em: <http://www.in.gov.br/visualiza/index.jsp?jorn $\mathrm{al}=1$ \&pagina $=259 \&$ data $=10 / 01 / 2000>$. Acesso em: 4 jul. 2013
BUENO, G.; BACCARIN, J.G. Participação das principais frutas brasileiras no comércio internacional: 1997 - 2008. Revista Brasileira de Fruticultura, Jaboticabal, v.34, n.2, p.424-434, 2012.

CARVALHO, D. Fruticultura: entraves à competitividade. Desavios, Brasília, p.51-59, 2009.

CHITARRA, M.I.F.; CHITARRA, A.B. Pós-colheita de frutos e hortaliças: fisiologia e manuseio. Lavras: UFLA, 2005. 785p.

COHEN, K.O.; SANO, S.M.; SILVA, J.C.S.; MELO, J.T. Avaliação das características físicas e físicoquímicas dos frutos de araticum procedentes de Cabeceiras-GO. Planaltina: Embrapa cerrados, 2010. 16p. (Documentos, 270.)

DAMIANI, C.; VILAS BOAS, E.V.B.; ASQUIERI, E.R.; LAGE, M.E.; OLIVEIRA, R.A.; SILVA, F.A.; PINTO, D.M.; RODRIGUES, L.J.; SILVA, E.P.; PAULA, N.R.R. Characterization of fruits from the savanna: Araça (Psidium guinnensis $\mathrm{Sw}$.) and Marolo (Annona crassiflora Mart.). Ciência e Tecnologia de Alimentos, Campinas, v.31, n.3, p.723-729, 2011.

FIGUEIREDO, M.A.P.; SOUZA, A.L.; MEIRA NETO, J.A.A.; SILVA, A.F.; FIGUEIREDO, L.G.A. Alteração estrutural de uma área de cerrado explorada sob regime de manejo no município de João Pinheiro Minas Gerais - Brasil. Revista Árvore, Viçosa, MG, v.34, n.3, p.521-528, 2010.

FILGUEIRAS, T.S.; BROCHADO, A.L.; NOGUEIRA, P.A.; GUALA II, G.F. Caminhamento - um método expedito para levantamentos florísticos qualitativos. Cadernos de Geociências, Rio de Janeiro, n.12, p.39-43, 1994.

INSTITUTO ADOLFO LUTZ. Métodos físicoquímicos para análise de alimentos. 4.ed. São Paulo, 2005. 1018p.

KROLOW, A.C.; SCHWENGBER, J.; FERRI, N. Avaliações físicas e químicas de morango cv. Aromas produzidos em sistema orgânico e convencional. Revista Brasileira de Agroecologia, Cruz Alta, v.2, n.2, p.1732-1735, 2007

LIMA, J.P.C.; LEÃO, J.R.A. Dinâmica de Crescimento e Distribuição Diamétrica de Fragmentos de Florestas Nativa e Plantada na Amazônia Sul Ocidental. Floresta e Ambiente, Seropédica, v.20, n.1, p.70$79,2013$. 
LIMA-BRITO, A.; BELLINTANI, M.C.; RIOS, A.P.S.; SILVA, J.R.S.; DONELLES, A.L.C. Morfologia de fruto, semente e plântula de três espécies de Annona (Annonaceae). Sitientibus Série Ciências Biológicas, Feira de Santana, v.6, n.2, p.119-128, 2006.

LOPES, R.M.; SILVA, J.P.; VIEIRA, R.F.; SILVA, D.B.; GOMES, I.S.; AGOSTINI-COSTA, T.S. Composição de ácidos graxos em polpa de frutas nativas do cerrado. Revista Brasileira de Fruticultura, Jaboticabal, v.34 n.2, p.635-640, 2012.

MARCELLINI, P.S.; CORDEIRO, C.E.; FARAONI, A.S.; BATISTA, R.A.; RAMOS, A.L.D.; LIMA, A.S. Comparação físico-química e sensorial da atemoia com a pinha e a graviola produzidas e comercializadas no Estado de Sergipe. Alimentos e Nutrição, Araraquara, v.14, n.2, p.187-189, 2003.

MOSCA, J.L.; CAVALCANTE, C.E.B.; DANTAS, T.M. Características botânicas das principais anonáceas e aspectos fisiológicos de maturação. Fortaleza: Embrapa agroindústria tropical, 2006. 28p. (Documentos, 106).

NEVES, C.S.V.J.; YUHARA, E.N. Caracterização dos frutos de cultivares de atemoia produzidos no norte do Paraná. Semina: Ciências Agrárias, Londrina, v.24, n.2, p.311-314, 2003.

OLIVEIRA, M.E.B.; GUERRA, N.B.; MAIA, A.H.N.; ALVES, R.E.; MATOS, N.M.S.; SAMPAIO, F.G.M.; LOPES, M.M.T. Características químicas e físico-químicas de pequis da Chapada do Araripe, Ceará. Revista Brasileira de Fruticultura, Jaboticabal, v.32, n.1, p.114-125, 2010.

PINTO, W.S.; DANTAS, A.C.V.L.; FONSECA, A.A.O.; LEDO, C.A.S.; JESUS, S.C.; CALAFANGE, P.L.P.; ANDRADE, E.M. Caracterização física, físico-química e química de frutos de genótipos de cajazeiras. Pesquisa Agropecuária Brasileira, Brasília, v.38, n.9, p.1059-1066, 2003.

SANTOS, M.A.; CAMARGO, M.B.P. Parametrização de modelo agrometeorológico de estimativa de produtividade do cafeeiro nas condições do Estado de São Paulo. Bragantia, Campinas, v.65, n.1, p.173-183, 2006.
SANTOS, M.B.; CARDOSO, R.L.; FONSECA, A.A.O.; CONCEIÇÃO, M.N. Caracterização e qualidade de frutos de umbu-cajá (Spondias tuberosa X S. mombin) provenientes do recôncavo sul da Bahia. Revista Brasileira de Fruticultura, Jaboticabal, v. 32, n.4, p.1089-1097, 2010

SILVA, F.H.L.; FERNANDES, J.S.C.; ESTEVES, E.A.; TITON, M.; SANTANA, R.C. Populações, matrizes e idade da planta na expressão de variáveis físicas em frutos de pequizeiros. Revista Brasileira de Fruticultura, Jaboticabal, v.34, n.3, p.806-813, 2012.

SILVA, J.; SILVA, E.S.; SILVA, P.S.L. Determinação da qualidade e do teor de sólidos solúveis nas diferentes partes do fruto de pinheira (Annona squamosa L.). Revista Brasileira de Fruticultura, Jaboticabal, v.24, n.2, p.562-564, 2002.

SILVA, P.S.L.; ANTONIO, R.P.; MARIGUELE, K.H.; SILVA, K.M.B.; LIMA, L.K.; SILVA, J.C.V. Estimates of genetic parameters for fruit yield and quality in custard Apple progênies. Revista Brasileira de Fruticultura, Jaboticabal, v.29, n.3, p.550-558, 2007.

SILVA, P.S.L.; MENEZES, J.B.; OLIVEIRA, O.F.; SILVA, P.I.B. Distribuição do teor de sólidos solúveis totais no melão. Horticultura Brasileira, Vitória da Conquista, v.21, n.1, p.31-33, 2003.

TELLES, M.P.C.; VALVA, F.D.; BANDEIRA, L.F.; COELHO, A.G. Caracterização genética de populações naturais de araticunzeiro (Annona crassiflora Mart. - Annonaceae) no Estado de Goiás. Revista Brasileira de Botânica, São Paulo, v.26, n.1, p.123-129, 2003.

VALE, V.S.; CRESPILHO, R.F.; SCHIAVINI, I. Análise da regeneração natural em uma comunidade vegetal de cerrado no parque Victório Siquierolli, Uberlândia-MG. Bioscience Journal, Uberlândia, v.25, n.1, p.131-145, 2009. 